\title{
Correction to: Coccidioidomycosis in a Pediatric Patient
}

\author{
Reginaldo Gonçalves de Lima-Neto • Cícero Pinheiro Inácio (D) \\ Ronyllton Brito Costa • Rossana de Aguiar Cordeiro - Wendell Wons Neves • \\ Rejane Pereira Neves • Oliane Maria Correia Magalhães • Armando Marsden Lacerda Filho • \\ Paulo Sergio Ramos de Araújo
}

Published online: 3 June 2021

(C) Springer Nature B.V. 2021

Correction to: Mycopathologia (2021) 186:137-139

https://doi.org/10.1007/s11046-020-00517-x

In the original publication of the article, few of the coauthor names were missed to publish, and the same has been provided in this correction.

The original article can be found online at https:// doi.org/10.1007/s11046-020-00517-x.

R. G. de Lima-Neto $(\bowtie) \cdot$ C. P. Inácio •

W. W. Neves · P. S. R. de Araújo

Departamento de Medicina Tropical, Universidade

Federal de Pernambuco (UFPE), Recife, Pernambuco,

Brazil

e-mail: reginaldo.limant@ufpe.br;

reginaldo.limaneto@pq.cnpq.br

C. P. Inácio · R. P. Neves · O. M. C. Magalhães ·

A. M. L. Filho

Departamento de Micologia, Universidade Federal de

Pernambuco, Recife, Pernambuco, Brazil

R. G. de Lima-Neto - R. B. Costa · P. S. R. de Araújo Hospital das Clínicas da UFPE, Recife, Pernambuco, Brazil

R. de Aguiar Cordeiro

Departamento de Patologia e Medicina Legal,

Universidade Federal do Ceará, Fortaleza, Brazil
Publisher's Note Springer Nature remains neutral with regard to jurisdictional claims in published maps and institutional affiliations. 